\section{HUMAN VARIETY.}

$\mathrm{T}$ would have been a pleasure to me in this address, given at the conclusion of my office as your President, to have cast a retrospect over the proceedings of our Institute during the four years that I have had the honour to hold it. But the subjects that have come before us are so varied that it seemed difficult to briefly summarize them in a manner that should not be too desultory.

On the whole, I thought it might be more useful if I kept to a branch of anthropometry with which many inquiries have made me familiar, and took the opportunity of urging certain views that seem to be worthy the attention of anthropologists.

Before entering upon these more solid topics, let me mention that the laboratory of which I spoke in my last address has been in work during the past year, and that about 1200 persons have been already measured at it in many ways, some more than once. I lay on the table a duplicate of one of the forms of application to be measured, and of one of the filled-up schedules. It will be observed that I now have the impressions made in printers' ink of the two thumbs of each person who is measured, being desirous of investigating at leisure the possibilities of employing that method for the purpose of identification, not forgetting the success that attended Sir W. Herschel's use of it in India, but conscious at the same time of practical difficulties. There is no doubt that the thumb or finger marks vary so much that a glance suffices to distinguish half a dozen varieties, while a minute investigation shows an extraordinary difference in small, though perfectly distinct, peculiarities. Neither is there any room for doubt that these peculiarities are persistent throughout life : nor, again, that so satisfactory a method of raising a very strong presumption of identity would be valuable in many cases. It will suffice to quote the following. A newspaper was lately sent me from the distant British settlement of North Borneo, where, owing to the wide and rapid spread of information nowadays, attention had been drawn to an account of a lecture I gave on one of the Friday evenings last spring, at the Royal Institution. It was on "Personal Description and Identification," and a writer in the British North Borneo Herald commented upon the remarks there made on finger imprints. He spoke of the great difficulty of identifying coolies either by their photographs or measurements, and that the question how this could best be done would probably become important in the early future of that country. I also am assured that the difficulty of identifying pensioners and annuitants has led to frequent fraud from personation, involving in the aggregate a very large sum of money annually, as there is good reason to believe. If finger imprints could be practically brought into use, such frauds would be extremely difficult. I am still unable to speak positively as to the best way of making them, but the plan adopted at the laboratory is as follows. A copper plate is smoothly covered with a very thin layer of printers' ink, a printers' roller being used, and the plate being cleaned every day. When the layer is thin, no ink penetrates into the delicate furrows of the skin, but the ridges only are inked, and these leave their impression when the inked thumb is pressed on paper. In this way a permanent mark is registered. A little turpentine cleans the fingers effectually afterwards. But for purposes of identification a simpler process is necessary, one by which a person suspected of personation could furnish an imprint for comparison with the registered mark without having recourse to the troublesome paraphernalia of the printer. Such a process is afforded by slightly smoking a piece of smooth metal or glass over the candle, pressing the finger on it, and then making the imprint on a bit of

${ }^{1}$ Address delivered at the anniversary meting of the Anthropological Institute, on Tuesday, January 22, by Mr. Francis Gaiton, F.R.S., President. gummed paper that is slightly damped. The impression is a particularly good one, and is sufficiently durable for the purpose. The iron used for the ironing of clothes is excellent for the purpose; even a smooth penny can be used. As for the gummed paper, luggage labels can be used; even the fringe to sheets of postage stamps is broad enough to include as much of the impression as is especially wanted namely, where the whorl of ridges takes its origin.

I hope at some future time to recur to this subject.

Correlation.- The measurements made at the laboratory have already afforded data for determining the general form of the relation that connects the measures of the different bodily parts of the same person. We know in a general way that a long arm or a long foot implies on the whole a tall staturc-ex pede Herculem; and conversely that a tall stature implies a long foot. But the question was as to whether that reciprocal relation, or correlation as it is commonly called, admitted of being precisely expressed. Correlation is a very wide subject indeed. It exists wherever the variations of two objects are in part due to common causes; but on this occasion I must only speak of such correlations as have an anthropological interest. The particular problem I first had in view was to ascertain the practical limitations of the ingenious method of anthropometric identification due to M. A. Bertillon, and now in habitual use in the criminal administration of France. As the lengths of the various limbs in the same person are to some degree related together, it was of interest to ascertain the extent to which they still admit of being treated as independent. The first results of the inquiry, which is not yet completed, have been to myself a grateful surprise. Not only did it turn out that the expression and the measure of correlation between any two variables are exceedingly simple and definite, but it became evident almost from the first that I had unconsciously explored the very same ground before. No sooner had I begun to tabulate the data than I saw that they ran in just the same form as those that referred to family likeness in stature, and which were submitted to you two years ago. A very little reflection made it clear that family likeness was nothing more than a particular case of the wide subject of correlation, and that the whole of the reasoning already bestowed upon the special case of family likeness was equally applicable to correlation in its most general aspect.

It may be recollected that family likeness in any given degree of kinship-say that between father and son-was expressed by the fact that any peculiarity in the father appears in the son, reduced on the average to just onethird of its amount. Conversely, however paradoxical it might at first sight appear, any peculiarity in a son appears in the father, also reduced on the average to one-third of its amount. The regression, as I called it, from the stature of the known father to the average son, or from the known son to the average father, was here from I to $\frac{1}{3}$; from the known brother to the unknown brother it was $\frac{2}{3}$; from uncle to nephew, or from nephew to uncle, it was $\frac{2}{9}$; and in kinship so distant as to have insensible influence, it was from 1 to o. Whether the peculiarity was large or small, these ratios remained unaltered. The reason of all this was thoroughly explained, and need not be repeated here. Now the relation of head-length to head-breadth, whose variations are on much the same scale, is of the same kind as the above. They are akin to each other in the same sense as kinsmen are. So it would be in the closer relation between the lengths of the corresponding limbs, left arm to right arm, left leg to right leg. The regression would be strictly reciprocal in these cases. When, however, we compare limbs whose variations are on different scales, these differences of scale have to be allowed for before the regression can assume a reciprocal form. The plan of making the requisite allowance is perfectly: 
simple, but I cannot explain it without using technical terms. In some cases this allowance is large; thus the length of the middle finger varies at so very different a rate from that of the stature that I inch of difference of middle-finger length is associated on the average with 8.4 inches of stature. On the other hand, Io inches of stature is associated on the average with 0.6 inch of middle-finger length. There is no reciprocity in these numerals; yet, for all that, when the scale of their respective variabilities is taken into account as above mentioned, the values at once become strictly reciprocal. I shall be able to explain this better later on.

In every pair of correlated variables the conditions that were shown to characterize kinship will necessarily be present--namely, that variation in one of the pair is on the average associated with a proportionate variation in the other, the proportion being the same whatever may be the amount of the variation. Again, when allowance is made for their respective scales of variability, the proportion is strictly reciprocal, and it is always from $\mathbf{I}$ to something less than I. In other words, there is always regression.

Variety.-The principal topic of my further remarks will be the claims of variety to more consideration from anthropologists than it has hitherto received. They commonly devote their inquiries to the mean values of different groups, while the variety of the individuals who constitute those groups is too often passed over with contented neglect. It seems to me a great loss of opportunity when, after observations have been laboriously collected, and been subsequently discussed in order to obtain mean values from them, the very little extra trouble is not taken that would determine other values whereby to express the var ety of the individuals in those groups. Much experience some years back, and much new experience during the past year, bas proved to me the ease with which variety may be adequately expressed, and the high importance of taking it into account. There are numerous problems of especial interest to anthropologists that deal solely with variety.

There can be little doubt that most persons fail to have an adequate conception of the orderliness of variability, and think it useless to pay scientific attention to variety, as being, in their view, a subject wholly beyond the powers of definition. They forget that what is confessedly undefined in the individual may be definite in the group, and that uncertainty as regards the one is in no way incompatible with statistical assurance as regards the other. Almost everybody is familiar nowadays with the constancy of the average in different samples of the same large group, but they do not often realize the way in which the same statistical constancy permeates the whole of the group. The Mean or the Average is practically nothing more than the middlemost value in a marshaled series. A constancy analogous to that of the Mean characterizes the values that occupy any other fractional position that we please to name, such as the Ioth per cent., or the 2oth per cent.; it is not peculiar to the 5oth per cent., or middlemost.

Greater interest is usually attached to individuals who occupy positions towards either of the ends of a marshaled series, than to those who stand about its middle. For example, an average man is morally and intellectually a very uninteresting being. The class to which he belongs is bulky, and no doubt serves to keep the course of social life in action. It also affords, by its inertia, a regulator that, like the fly-wheel to the steam-engine, resists sudden and irregular changes. But the average man is of no direct help towards evolution, which appears to our dim vision to be the primary purpose, so to speak, of all living existence. Evolution is an unresting progression; the nature of the average individual is essentially unprogressive. His children tend to resemble him exactly, whereas the children of exceptional persons tend to regress towards mediocrity. Consider the interest attached to variation in the moral and intellectual nature of man, and the value of variability in those respects. For example, in the Hebrew race, whose average worth shows little that is worthy of note, but which is mainly of interest on account of its variety. Its variability in ancient and modern times seems to have bcen extraordinarily great. It has been able to supply men, time after time, who have towered high above their fellows, and left enduring marks on the history of the world.

Some thoroughgoing democrats may look with complacency on a mob of mediocrities, but to most other persons they are the reverse of attractive. The absence of heroic gifts is a heavy set-off against the freedom from a corresponding number of very degraded forms. The general standard of thought and morals in a mob of mediocrities must be mediocre, and, what is worse, contentedly so. The lack of living men to afford lofty examples, and to educate the virtue of reverence, would leave an irremediable blank. All men would find themselves at nearly the same dead average level, each as meanly endowed as his neighbour.

These remarks apply with obvious modifications to variety in the pbysical faculties. Peculiar gifts, moreover, afford an especial justification for division of labour, each man doing that which be can do best.

The method I have myself usually adopted for expressing and dealing with the variety of the individuals in a group, has been already explained on more than one occasion. I should not have again alluded to it had I not had much occasion of late to test and develop it, also to devise an unpretentious little table of figures, that I call a "table of normal distribution," which has been of singular assistance to myself. I trust it may be equally useful to other anthropologists. It is appended to these remarks, and I should like after a short necessary preface to say something about it. The table and its origin, and several uses to which it has been applied, will be found in a book by myself, that will be published in a few days, called "Natural Inheritance" (Macmillan and Co.). All the data to which I shall refer will be found in that book also, except such as concern correlation. These accompanied a memoir read by me only a month ago before the Royal Society, and will be published in due course in their Proceedings. ${ }^{1}$

It has already been said that the first step in the problem of expressing variety among the individual members of any sample, is to marshal their measures in order, into a class. We begin with the smallest measure and end with the greatest. The object of the next step is to free ourselves from the embarrasment due to the different numbers of individuals in different classes. This is effected by dividing the class, whatever its size may be, into roo equal portions, calling the lines that divide the portions by the name of grades. The first of these portions will therefore lie between grades $0^{\circ}$ and $1^{\circ}$, and the hundredth and last portion between grades $99^{\circ}$ and $100^{\circ}$. We have next to find by interpolation the values that correspond to as many of these grades as we care to deal with. It is of no consequence whether or no the number in the class is evenly divisible by 100 , because we can interpolate and get the values we want, all the same. This having been done, the value that corresponds with the 5oth grade will be the middlemost. It is practically the same for ordinary purposes as the mean value or the average value; but as it may not be strictly the same, it is right to call it by a distinctive name, and none simpler or more convenient occurs than the letter M. So I will henceforth use $M$ to denote the middlemost or median value, or, in other words, that which corresponds to the 5oth (centesimal) grade.

The difference between the extreme ends of a marshaled

I For abstract, see Nature, January 3. p. 238 . For tables of percentiles, see vol. xxxi. p. 223. For hereditary stature, see vol. xxxiii. p. 295. 
series is no proper measure of the variety of the men who compose it. However few in number the objects in the series may be, it is always possible that a giant or a dwarf, so to speak, may be among them. The presence of either would mislead as to the range of variety likely to be found in another sample taken from the same group. The values in a marshaled series run with regularity only about its broad and middle part ; they never do so in the parts near to either of its extremities. In a series that consists of a few hundreds of individuals, the regularity usually begins at about grade $5^{\circ}$, and continues up to about grade $95^{\circ}$. Therefore it is out of this middle part, between $5^{\circ}$ and $95^{\circ}$, or better, in a still more central portion of it, that points should be adopted between which variety may be measured. Such points are conveniently found at the $25^{\text {th }}$ and the $75^{\text {th }}$ grades. Just as the grade $50^{\circ}$ divides the class into two equal parts, so the grades $25^{\circ}$ and $75^{\circ}$ subdivide it into quarters, and the difference between those values affords an irreproachable basis for the unit of variety. The actual unit is half the value of that difference, because the value at $25^{\circ}$ tends to be just as much below that at $50^{\circ}$, as the value at $75^{\circ}$ is above it. Therefore the average of these two values is a better measure than their sum. Briefly, if we distinguish the measure at $25^{\circ}$ by the letter $Q_{1}$, and that at $75^{\circ}$ by $Q_{3}$, then the unit of variety is $\frac{1}{2}\left(Q_{3}-Q_{1}\right)$, and this unit we will henceforth call $\mathrm{Q}$. As $\mathrm{M}$ measures the average, so $\mathrm{Q}$ measures the variety, and they are independent of one another. In strength, for example, the relation of $Q$ to $M$ in the particular group of adult males on which I worked was as I to IO; in the statures of the same group it was as I to 40 ; in breathing capacity as I to 9 ; in weight as I to I4.

The aritbmetic mean or average is a muddle of all the values in the series; it is by no means so clear an idea as the middlemost value $M$. Therefore, although the peculiarities of an individual are commonly considered in the light of deviations from the average value, I prefer to reckon them as deviations from M. Practically the two methods are identical, but I find the latter more convenient to work with, and believe it to be the better of the two in every way.

Deviation is identical with variation, and the well-known law of frequency of error gives data whence the relative values of the deviations at the several grades may be calculated for any normal series. If we know the deviation at any one grade, then the absolute value of those at every other grade can be calculated; consequently the variety of the whole series is thereby expressed.

The small table of distribution, of which I spoke, gives the values at each grade when $Q$ is equal to $I$. Then the value at $25^{\circ}$ is $-\mathrm{I}$, and that at $75^{\circ}$ is $+\mathrm{I}$. If we desire to determine $Q$ in any such series, the only required datum is the deviation at some one known grade, since, by dividing that deviation by the tabular value, we get () at once. Or, conversely, if we know the $Q$ of the series, and wish to calculate the deviation at any given grade, we multiply $Q$ by the tabular deviation. Thus, in stature, which varies in an approximately normal manner, the value of $Q$ is about $I 7$ inch, therefore to find the devia tion in stature at any grade, we multiply $I \cdot 7$ inch by the tabular value.

If we know the measures at any two grades of a normal series, we are easily able to calculate both $Q$ and $M$, and can thence derive the measures at any other desired grades. I have long since pointed out the possibility of it traveller availing himself of this method; but, for the want of a table of distribution, the calculation would prohably puzzle him. With the aid of this table the calculation is made most readily. Let us suppose that the traveller is among savages who use the bow, and that he desires to learn as much as he can about their strengths. He selects two bows; the one somewhat easy to draw, and the other somewhat difficult, and at leisure, either before or after the experiment, he ascertains exactly how many pounds weight they severally require to draw them to the full. Then by exciting emulation, and by offering small prizes, he induces a great many of the natives to try their strengths upon them. He notes how many make the attempt, and how many of them fail in either test. This is all the observation requisite, though common-sense would suggest the use of three and not two bows, in order that the data from the third bow might correct or confirm the results derived from the other two. Let us work out a case, not an imaginary one, but derived from tables I have already published, and of which I will speak directly. Let the problem be as follows :-..

30 per cent. of the men failed to exert a pulling strength of 68 pounds; 60 per cent. failed to pull 77 pounds. What is the $Q$ and the $M$ of the group?

Consider this 30 per cent. to be the exact equivalent of grade $30^{\circ}$, and the 60 per cent. of grade $60^{\circ}$. The reason why the percentage of failure, and the number of the grade are always equivalent will be found in a footnote to the table, and I need not stop to speak of it. Now, the tabular value at grade $30^{\circ}$ is -0.78 ; that at $60^{\circ}$ is +0.38 ; the difference between them being I'I 6 On the other hand, the difference between the two test values of 68 pounds and 77 pounds is 9 pounds. Therefore $\mathrm{Q}$ is equal to 9 pounds divided by 1.16 ; that is, to 7.8 pounds. M may be obtained by either of two ways, which will always give the same answer. We may subract $0.38 \times 7.8$ pounds from 77 pounds, or we may add $0.78 \times 7.8$ pounds to 68 pounds. Each gives 74 pounds. Observation gave precisely these values both for $Q$ and for M. The data were published in the Journal of this Institute as a table of "percentiles," and were derived from measures made at the International Health Exhibition. The value of $\mathrm{M}$ is given directly in the table, but that of () happens not to be given there; it may easily be found by interpolation. That table affords excellent material for experimental calculations on the principle of this test, and for estimating its trustworthiness in practice.

It contains a variety of measures referring to eighteen different series, all corresponding to the same gradesnamely, to $5^{\circ}, 10^{\circ}, 20^{\circ}$, and onwards for every tenth grade up to $90^{\circ}$ and ending with $95^{\circ}$. The measures refer to stature, height sitting above seat of chair, span, weight, breathing capacity, strength of pull, strength of squeeze, swiftness of blow, keenness of eyesight, in each case of adult males and of adult females separately. I have since found that when the deviations are all reduced in terms of their respective $\mathrm{Q}$ values, by dividing each of them by its $(2$, that the average value of all the deviations at each of the grades in the eighteen series closely corresponds to the normal series, though individually they differ more or less from it, some in one way, some in another. On the whole, the error of treating an unknown series as if it were a normal one can rarely be very large, always supposing that we do not meddle with grades lower than $5^{\circ}$ or higher than $95^{\circ}$.

It will be of interest to put the comparison on record. It is as follows :-

\begin{tabular}{|c|c|c|c|c|c|c|c|c|}
\hline Grades & $\ldots$ & $\ldots$ & $5^{\circ}$ & $10^{\circ}$ & $20^{\circ}$ & $30^{\circ}$. & $40^{\circ}$ & $50^{\circ}$ \\
\hline Observed & $\ldots$ & $\cdots$ & $-2 \cdot 44$ & $-I .87$ & $-I^{\prime} 24$ & -0.77 & -.040 & 0 \\
\hline $\begin{array}{r}\text { Normal } \\
- \text { below } 5 \\
+ \text { above } 5\end{array}$ & $\left.50^{\circ}\right\}$ & $\ldots$ & $2 \cdot 44$ & I'9o & $x \cdot 25$ & 0.78 & $0.3^{8}$ & 0 \\
\hline Observed & $\ldots$ & $\ldots$ & $+2 \cdot 47$ & $+I^{*} \cdot 92$ & $+r^{\prime} 21$ & +0.75 & $+0 .{ }_{3}^{8}$ & 0 \\
\hline Grades & $\cdots$ & $\cdots$ & $95^{\circ}$ & $90^{\circ}$ & $80^{\circ}$ & $70^{\circ}$ & $60^{\circ}$ & $50^{\circ}$ \\
\hline
\end{tabular}

The "observed" are the mean values, made as abuve described, of the eighteen series; the "normal" are taken from the table of distribution given further on. 
An ingenious traveller might obtain a great number of approximate and interesting data by the method just described, measurios various faculties of the natives, such as their delicacy of cy esight and hearing, their swiftness in running, their accuracy of aim with spear, arrow, boumerang, sling, gun, and so forth, either laterally or else verticilly, distance of throw, stature, and much else. but he should certainly use three test objects, and not two only:

It should be remarked that, if the distribution of deviation was constant throughout any large class of faculties, though the ( $)$ might differ in different sub-classes of it, then, even though the distribution of that faculty was very far indeed from being normal, an appropriate table of distribution cauld be drawn up to solve such problems as those mentioned above. I have as yet no accurate data to put this idea to a practical test.

There are three convenient stages of expressing the variets of the various measures in a series, each reachine considerably nearer to precision than the one before. The first is to give only (2) and $\mathrm{M}$; the second is to record the measures at the grades $10^{\circ}, 25,50^{\circ}, 75^{\circ}$, and 90 ; the third is the more minute method, adopted in the table of percentiles-viz. to give the measures at 5 , 10, 20, \&c., So', 90", and 95. It may in some cases be found worth while to go further, say to $1^{\circ}$ and $99^{\circ}$, or even also to 0 and $99^{\circ} \%$. So much for the expression of variets.

The lise of () is by no means limited to the objects just mance. It is a necessitry datum whereser the law of frequer:cy of crror lies $t$ ) be applied, and the properties of this law are applicable to a very large number of antleropological prebloms, with more accuracy of result than might have been anticipated when the series are only approxim.tively normal. This has been practically shown by the arreement among themselses of several inquiries to which I will shortly allude, and it is theoretically defensible by two considerations. The or $\mathrm{e}$ s that the law of frequency supposes the amount of error or of deviation to be the salne in simmetrically disposed sades on either side of 50, their signs being alone different, minus on the one sicle of $5^{\circ}$ and plus on the other. Now; in an observed series there may be, and often is, a want of symmetry, but if the deviate, say at $70^{\circ}$, is as much greater than the normal as the deviate at $30^{\circ}$ is less than the normal, then the effects of these two upon the final result will be untuch the same ats if there had been exact simmetry at those points. The other consideration is that any nonconformity of the observed deviates with the theoretical ones towards the end of the series has but a small and perhaps insensible effect on the broad general conclusions $11 \mathrm{c}$ need care little for any vagaries outside of the grades 5 and 95 , if the intervening portion gives fairly good results. The latter portion forms nine-tenths of the whole series, and even considerable irregularities in the remaining tenth are of small relative importance.

One great use of $Q$ is to enable us to es:imate the trustworthness of our average results. We require to know both (? and the number of observations before we can estimate the degree of dependence to be placed on M. If there was only one observation, then the degree of dependence would be equal to $(2$; in other words, the error of $M$ would be just as likely as not to exceed (). If there were two, two hundred, two thousand, or any other number of observations, the error of $I I$ would then be reduced, but not in simple proportion. It would be as likely as not to exceed a value equal to () divided by the square roots of those numbers. When we desire to ascertain the trustworthiness of the difference between the $M$ values of two series, as between the mean statures of the professional and artisan class as derived from certain observations, the properties of the law of frequency of crror must again be appealeci to. Anthr.pologists are much en ared in studying such ditierences as these; but from their disregard of the simple datum (), and from not being familiar with its employment, there is usually a lamentable and quite unnecessary vagueness in the value to be attached to their results. Thi; is especially the case in comparisons between the average dimensions of the skulls of various races, which often depend upon the measurement of only a few specimens. An almost solitary exception to this needless laxity will be found in a brief but admirably-expressed memoir by I.)r. l' $n$ n, the wellknown author of the "Logic of Chance." It is upon Cambridge anthropometry, and was published in the last number of the Journal of this Institute. It deserves to be a model to those who are engraged in similar inquiries.

Another class of investigations in which a knowledge of $Q$ is essential was spoken of some time back-namely questions of correlation in the widest sense of the word. 'These problems have nothing to do with the relations of the M value, but are solely concerned with those of the deviations from $\mathrm{M}$ at the various grades. It is true that a knowledge of $\mathrm{II}$ is requisite in order to subtract it from the measures, and so to get at the deviations. But after this is done, $M$ is put aside. It has no part in the work of the problem ; it is only after the results have been arrived at without its use that it is again brought forwaril and added to them. Numerous properties of the law of frequency of error in which () is the datum were utilized in my in. quiries into family likeness in stature, and in all cases they brought out consistent results. An excellent example of this was seen in the success of the methods emploved to determine the variety in families of brothers. Four different properties of the law had to be applied to partt different samples of the same sroup in order to deternine the value of the () of stature in fraternities, and ther respectively gave $107,0.98,1 \cdot 10$, and 1.10 inch, which, statistically speaking, are much alike. Certain propertics of the law of frequency of error were also applied to family likeness in cye colour, with results that gave by calculation the total number of light-eyed chikdren in families differently grouped according to their parentage ancl grandparentage, and according to three different sets of data, as 623, 601, and 6It respectively, the observed number heing 620. Other properties of the same law have been applied to determine the ratio of artistic to nonartistic children in families whose parentages were known to be either both artistic, onc artistic, one not, or neither artistic. They gave to 1507 children the ratios of 64.39 , and 21 , respectively, as against the observed values of 60 , 39. and 17 .

latstly, as recrards the correlation of lengths of the different limbs. It has already been shown that the correliation lies between the deviations, and has nothing todo with the values of .11 . Now, to express this relation truly, so that it shall be reciprocal, the scale of deviation of the correlated limbs, say, for example, of the cubit and of the st ature, must be reduced to a common standard. W'e therefore reduce them severally to scales in each of which their own (? is the unit. The of the cubst is 0.56 ach, therefore we divide each of its deviations by of 5 . The () of the stature is $\mathrm{J} 75$ inch, so we divide ench of its deviations by 175 . When this is done the correlation is perfect. The value of regression is found to be $0: 8$, whether the cubit be tatien as the "subject" and the mean of the corresponding statures as the "relative," or aici rerstí.

The value of the regression has been ascerlained for each of many pairs of the following elements, and a comparison was made in each case between the correlated values as observed and those calculated from the ratio of regression. The coincidence was close throughout, quite as much so as the small number of cases under cxamination, 3 jo in all, could lead us to hope. The elements were nine in all, viz. head-length, breadth of head, length of right les below the knee, of left cubit, of left micklle finger, of the height sitting above the chair, of 
stature, of the differences between the two foregoing (which indicate the total length of the lower limbs), and of the span. Anthropologists seem to have little idea of the wide fields of inquiry open to them as soon as they are prepared to deal with individual variety and cease to narrow their view to the consideration of the average.

Enough has now been said to justify the claims with which I started, and which take this final form. First, wherever it is likely to be of use, that, in series of which the $M$ is calculated, the measures at a certain number of selected grades should also be calculated and given, sufficient to enable the rest of the series to be found with adequate accuracy by interpolation. Secondly, that the value of $Q$ should always be given, as well as that for $M$, for two reasons. The one is, that they suffice between them to give an approximate determination of the whole series, more closely approximate as the series is more closely of the normal type ; and, secondly, because $Q$ is an essential datum before any application can be made of the law of frequency of error. The properties of this law are, as we have seen, largely available in anthropological inquiry. They enable us to define the trustworthiness of our results, and to deal with such interesting problems as those of correlation and family resemblance, which cannot be solved without its help.

Table of ordinates to normal iurve of distribution, in which the unit = the probable error, and the grades, which are the abscisse, run from $0^{\circ}$ to $100^{\circ}$.

\begin{tabular}{|c|c|c|c|c|c|c|c|c|c|c|}
\hline Grades. & o & I & 2 & 3 & 4 & 5 & 6 & 7 & 8 & 9 \\
\hline 0 & $\infty$ & -345 & -305 & -279 & -2.60 & -2.44 & $-2^{1} 3^{I}$ & $-2 \times 9$ & $-2 \cdot 08$ & $-\mathrm{I}$ \\
\hline 10 & $-r .90$ & -1.82 & $-\mathrm{I} \cdot 74$ & $-x^{6} 67$ & $-1.6 c$ & $-\mathrm{I} 54$ & $-I^{4} 47$ & $-\mathrm{I}^{\prime} 42$ & $-\mathbf{I}^{*} 3 \mathrm{E}$ & \\
\hline 20 & $-x \cdot 25$ & -120 & $-I_{15}$ & -1.10 & -1.05 & -100 & -0.95 & $|-0.9 \mathrm{I}|$ & -0.86 & \\
\hline 30 & -0.78 & $-0^{\prime} 74$ & $-0^{\circ} 69$ & -0.65 & -0.61 & -0.57 & $-0^{\circ} 53$ & -0.49 & $-0^{\circ} 45$ & \\
\hline 40 & -0.38 & $-0^{\circ} 34$ & $\mid-0^{\circ} 30$ & -0.26 & -0.22 & - o.10 & $-0 \times 5$ & -0.12 & -0.07 & -0 \\
\hline 50 & 0.00 & $+0^{\circ} \mathrm{O}_{4}$ & $+0^{\circ} 07$ & to 11 & $+0 \times 5$ & to.19 & $+0^{\circ} 22$ & +0.26 & to 30 & \\
\hline 60 & $+0.3^{8}$ & $+0_{4} 4 \mathrm{r}$ & +0.45 & +0.49 & $+0^{\circ} 53 \mid$ & +0.57 & +0.61 & +0.65 & +0.69 & \\
\hline 70 & +0.78 & $\mid+0.82$ & +0.86 & +0.91 & +0.95 & +100 & $+r^{\circ} 05$ & +r.ro & $+\mathrm{I}^{\prime} 15$ & \\
\hline 80 & +1.25 & $+I^{\prime} 30$ & $+\mathrm{I} \cdot 36$ & +142 & & $\mid+I .54$ & $+x^{2} 60$ & $+x^{\prime} 67$ & +r'74 & $+I$ \\
\hline 90 & +199 & & & +2.19 & +231 & $+22^{\circ}$ & +260 & $+2^{\prime} 79$ & +305 & +3 \\
\hline
\end{tabular}

This table is an inverse rendering of the values derived by interpolation from the ordinary table of the probability integral, but its unit is changed from that of the modulus to that of the probable error, $Q$, and the (centesimal) grades are reckoned from $o^{\prime}$ to roo $^{\prime \prime}$. In the usual way of reckning, the 5oth on the one side down to $-50^{\circ}$, and on the other up to $+50^{\circ}$.

Referring to what was said some way back, that if 30 per cent. fail to ful 60 pounds, then $\epsilon_{0}$ pounds must be taken as the measure corresponding to grade $30^{\circ}$, the reason is as follows. The zoth grade separates the man who ranks 3 oth in a class of 100 men from his neighb ur who ranks 3 Ist. It does so for the same reason that grade $I^{2}$ separates the man who ranks Ist from the man who ranks and. Now, the soth man failed in the test, and the $3^{\text {rst }}$ succeeded. Therefore the grade corresponding to bare success lies between them, and is the same as grade $30^{\circ}$.

\section{SUPPOSED FOSSILS FROM THE SOUTHERN} HIGHLANDS.

$\mathrm{O}^{\mathrm{N}}$ Monday, the r4th instant, the Royal Society of Edinburgh held a special meeting for the purpose of hearing a discussion on the crystalline rocks of the Scottish Highlands. The subject was brought forward by the Duke of Argyll, who had found in the quartzite beds which cross Loch Fyne near Inveraray certain markings which he believed to be of organic origin. His attention was first called to some ferruginous stalklike incrustations on the surfaces of fragments of quartzite, his impression being that these markings were the remains of plants, and were embedded in the rock. The importance of the discovery of organic remains in any of the rocks that form the Central and Southern Highlands of Scotland will at once be recognized by geologists. Since the recent work of the Geological Survey in Sutherland and Ross, and the demonstration thereby afforded that the apparent upward succession on which Murchison relied, from the base of the lowest quartzite up into the upper or eastern or younger gneisses, is deceptive, there has been, perhaps, a tendency to assume that the extraordinarily complicated structure that supervenes to the east of the quartzites and limestones of Sutherland extends across the whole of the rest of the Highlands, and that the crystalline schists of these regions are made up of all kinds of crushed and sheared igneous or sedimentary masses, out of which it may be impossible to make anything like intelligible order. But those observers who have themselves examined the schists of the central and southern counties of the Highlands are tolerably confident that such assumptions have no warrant in the actual structure of the ground. On the contrary, they regard the greater proportion of the schistose and altered rocks of these districts as unquestionably of sedimentary origin. They feel persuaded that sooner or later they will be found to yield fossils, and that any day may bring to light a series of corals, shells, graptolites, or trilobites, which will furnish a palæontological basis for settling the geological age of the rocks, and placing them in their true position with regard to the Palæozoic formations of the rest of the country.

The announcement that the Duke of Argyll had found what seemed to be organic remains in the Inveraray quartzites awakened accordingly much interest among geologists. His Grace soon discovered, however, that what he had at first believed to be fossils were only external markings due to the precipitation of hydrous peroxide of iron round the decaying stems of mosses, heaths, or other plants. These markings occurred indifferently on pieces of quartzite, mica-schist, gneiss, \&c., and in no instance were found within the stone, but always on the surface. But in turning over the exposed blocks of quartzite the Duke found numerous ferruginous markings which undoubtedly occurred all through the interior of the rock. After quarrying away portions of the solid rock, collecting a large series of specimens, and comparing them with others obtained from the quartzite of Sutherland, he deemed himself in a position to announce the probably organic nature of these markings; and the paper which he communicated last week to the Royal Society of Edinburgh gave the results of his inquiries. The bodies which he regards as fossils are compared by him to the "annelid burrows" which form so prominent a feature in the quartzites of Sutherland and Ross. He recognizes in the Inveraray rock similar ovate sections, the position and form of each tube being marked by a ferruginous ring, which is well defined along its inner margin, but fades outward into a general discoloration of the stone. He points out that in the Inveraray rock, as in that of the North-West Highlands, there is a general tendency of these ovate bodies to lie in one prevalent direction; and though he admits that the rocks have been considerably disturbed and crushed, he cannot trace among them any evidence of such stupendous movements as have been described from Sutherland. Accordingly he is disposed to look upon the parallelism of the stripes into which he thinks the original tubes have been flattened as evidence of the direction in which the worms burrowed through the still soft sand.

Perhaps the most original and valuable part of the Duke's paper was the account which he gave of his own experiments on the habits of the common lob-worms of our present shores. He had watched the operations of these creatures on the beach of dark silt at Inveraray; had cut out portions of the silt with the burrows and mounds intact, and had these removed to his own drawing-room to enable him to watch them more attentively. He had likewise injected plaster of Paris into the vertical or winding passages made by the worms in the silt, and had thereby obtained casts of the interior of these tunnels. He exhibited a very interesting and valuable collection of specimens illustrating these researches.

Mr. Geikie, the Director-General of the Geological 